\title{
A Preceding Study on Drive System of the Ropeless Elevator
}

\author{
Youn-Hyun $\mathrm{Kim}^{1^{*}}$ and Sol-Kim ${ }^{2}$ \\ ${ }^{1}$ Dept of Electrical Engineering, Hanbat University, \\ ${ }^{2}$ Dept of Electrical Engineering, Yuhan University \\ 로프리스 엘리베이터 구동시스템 선행연구 \\ 김윤현 ${ }^{*}$, 김 솔 ${ }^{2}$ \\ ${ }^{1}$ 한밭대학교 전기공학과, ${ }^{2}$ 유한대학교 전기공학과
}

\begin{abstract}
This paper suggests a preceding study to introduce implementing problems and improving direction when commercializing a ropeless elevator. In this study, the implementation of the study of pilot systems in order to produce the ropeless elevator and also build a linear velocity sensor, this system is applied to the speed control experiment was investigated through testing. Speed control test is carried out in all track including a curved section. This study verified the feasibility of the ropeless elevator and its drive controller is good enough to be accepted. This study also extracted many more problems that still need to be improved in the future for commercializing such as the sensor, high-performance controller, precision structures, safety devices, efficiency improvements and so on.
\end{abstract}

요 약 본 논문은 로프리스 엘리베이터의 상용화에 앞서 로프리스 엘리베이터의 기반 및 요구기술과 개발 시의 문 제점 및 개선방향을 제시하기 위한 선행연구를 제안한다. 본 연구에서는 연구의 구현을 위하여 로프리스 엘리베이터 를 소형시스템으로 제작하고 또한 자체 리니어 속도센서를 제작, 본 시스템에 적용하여 속도제어 시험을 통하여 문제 점을 검토하고자 한다. 속도제어는 곡선구간을 포함한 전 영역에 걸쳐 수행하였으며, 본 연구의 수행 결과 로프리스 엘리베이터의 실현 가능성을 확인하였으며 구동제어 기술의 만족할 만한 결과를 얻었다. 하지만 현재의 기술적인 수 준에서는 상용화를 위해 센서, 고성능 제어기, 정밀 구조물, 안전장치, 효율향상 등 향후에도 더욱 개선되어야 할 여 러 가지 문제점도 도출할 수 있었다.

Key Words : Curved Type Linear Motor, Linear Synchronous Motor, Ropeless Elevator System, Primary Switch System

\section{Introduction}

In recent years, there has been an increase in the number of high-rise and large-scale buildings; however, countless application problems exist on the rope elevators in buildings that are more than $200 \mathrm{~m}$ high. First of all, occupancy rate of the elevator increases directly proportional to the number of floors of the building, and secondly, the building cannot go over than $800 \mathrm{~m}$ because of the number of the ropes per diameter of the rope and administrative limits. Also, as the length of the rope increases, the modulus of elasticity decreases, causing vibration and a difficulty in control; the volume of the drive must increase also due to the weight increase of the rope. Third problem stems from the elevator waiting and riding times. Also, methodological and technical solutions for vertical, as well as horizontal, transportation are required [1].

${ }^{*}$ Corresponding Author : Youn-Hyun Kim(Hanbat Univ.)

Tel: +82-42-821-1099 email: yhyunk@hanbat.ac.kr

Received September 23, 2013 Revised November 13, 2013 Accepted January 9, 2014 
As a result, research on the ropeless elevators, a transportation application that utilizes linear motor for multiple elevator cars in one shaft, has been introduced as an alternative to the conventional rope-type elevator systems [2-9]. Earlier researches have only dealt with a guide system that can keep a certain air-gap and the applications of superconductivity [2-5]. However, most of the researches on the ropeless elevators are focused on designing linear motors and their drives [6-8]. Since linear motor does not require a mechanical structure that converts rotational drive to linear drive, it overcomes performance degradation like friction and noise. It seems to be the best drive motor that can perform vertical movements, unlike the rotary motors. Based on previous studies, there have been a numerous research articles on linear drives for the ropeless elevators; however, there is a lack of study on the solution of the linear drive system considering the overall of the ropeless elevator system.

In this paper, the problem in perspective ropeless elevator system can be a part of what the whole system to investigate the a small prototype designed to perform the test drive, and the future problems that may occur during development the ropeless elevator technology derived and requirements were It also provides direction for the commercialization to improve the previous studies were performed.

\section{LSM design for the Ropeless Elevator}

\subsection{Outline of the Ropeless Elevator}

Fig. 1 demonstrates a basic structure of the ropeless elevator. In this picture, multiples cages in one shaft can not only move at the same time, but also travel vertically and horizontally since there is no rope presented in the system. On the wall of the shaft, a primary coil is attached, and the cage with permanent magnets is in a moving magnet form. In order to excite the primary coil where the cage stands, it is structured so that the primary coil is divided up into segments and the power is supplied. In order to satisfy the design structure of the ropeless elevator, linear motor was used, allowing multiple numbers of cages in one shaft. A circulatory drive and passing drive are also possible, and as a result, the area of the elevator decreases, improving the spatial efficiency and elevator riding time.

In order to realize the ropeless elevator system in contrast with the existing one, following techniques should be additionally employed.

First of all, since there is no counterweight in ropeless elevators, there is too much energy consumption when elevator ascends because the overall weight of the cage is loaded. Therefore, a drive controller and energy conservation device that can use the energy from the descending period for the ascending time should be installed, and the weight of the cage should be decreased maximally in order to reduce the energy loss. Secondly, an accident of fall should be prevented through a regenerative braking of the motor itself, other than just using the mechanical brakes. Lastly, a contactless power supply is needed to provide power (button, lamp, etc) to the interior cage, and the information (speed, position, floor elevator) of each cage should be delivered to the main controller through wireless communications.

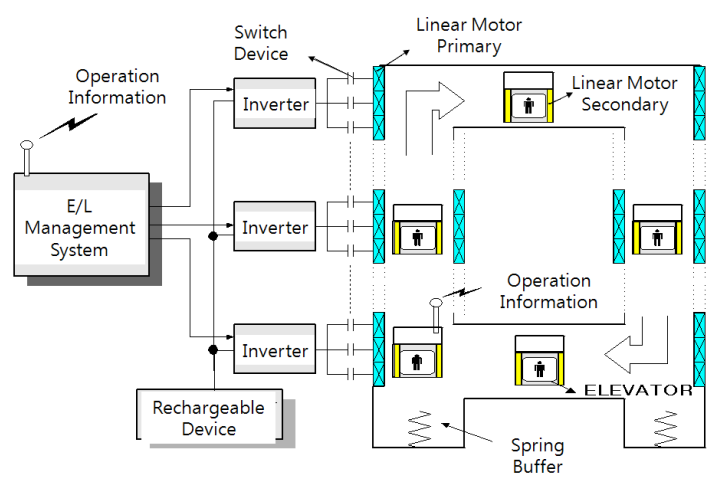

[Fig. 1] The ropeless elevator block diagram

\subsection{LSM Design}

For the curved sections, the ropeless elevator needs a drive that can perform a rotary drive, in which moving on and between the horizontal and the vertical sections is continuous, as seen in Fig. 1. In this research, linear synchronous motor (LSM), the drive motor, is investigated by differentiating the straight section and curved section. Since the straight section has already been dealt with in other research studies, this paper will state a conclusion for the straight section and mainly focus on 
the design and production processes of the curved section that has not been mentioned in existing studies.

In designing the straight part, the secondary part ambulator made by a permanent magnet is a quadrupole. The primary stator is a 15 pole with a synchronous speed of $0.25[\mathrm{~m} / \mathrm{s}$ ], efficiency $80[\%]$, power factor $90[\%]$, phase voltage $10[\mathrm{~V}]$. In these conditions the maximum weight capability is $15[\mathrm{Kg}]$, in other words to verify the possibility to make a rope-less elevator with double-side linear motors on the side with the specs of thrust of $100[\mathrm{~N}]$, rated output of $25[\mathrm{~W}]$.

The pole pitch is $30[\mathrm{~mm}]$, rated frequency is $4.17[\mathrm{~Hz}]$ using a Nd-Fe-B type permanent magnet determining the operating point, useful magnetic force per pole. Determining of the number of turns and slots, size of the tooth was based on general design methods of a permanent magnet motor.

In designing the curved part it is different with designing the straight part, as it can be seen in fig. 2 the thrust generated in the effective section area of the armature and the movement decreases. The armature radius has to be determined in order to maintain the effective section area. Depending on the type of the curve part in the movement field, the center and the curved part of the movement field's armature matches as it passes through the curved part. At the field resist side the armature and the field magnetic flux density intersection would be like a skew effect and show phase difference in magnetic field density.

As a result this is directly related with the decrease in the thrust. Seek how much the thrust decreases as the radius of the curved part is changed and find the most suitable radius.

The movement field and the curved parts armature center have a mechanical twist angle of $\theta_{m n}$ then the twist length is $h \cdot \sin \theta_{m n}$ from fig. 3. Regularly the skew angle, called $\theta_{s n}$, and the skew factor can be converted by the next equation.

$$
\begin{aligned}
\theta_{s n} & =\frac{h}{\tau} \pi \cdot \sin \theta_{m n} \\
& =2 \pi \times \sin \left(\sin ^{-1}\left(\frac{15 \times(2 n-1)}{R}\right)\right)
\end{aligned}
$$

The $n$ in equation (1) is the number of each magnet in fig. 2 .
As a result in designing the straight part, using the provided measurements of the movement field and applying the constraint condition. The amount of thrust decrease in a four pole is calculated like fig. 4.

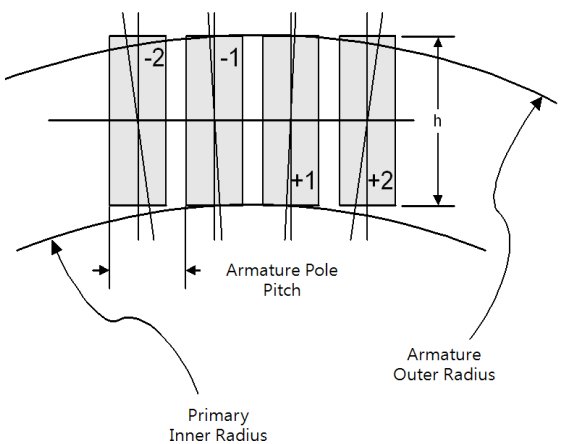

[Fig. 2] A moving field magnet in the curve

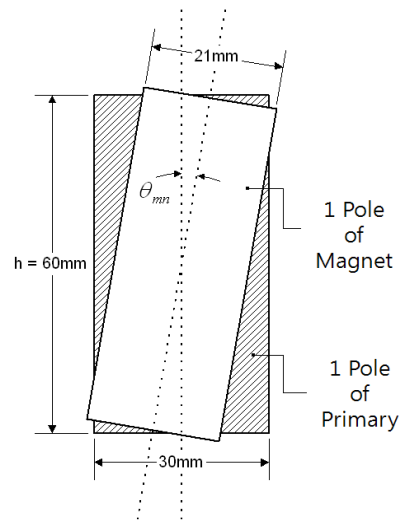

[Fig. 3] Unalignment between the moving field magnet and the curve

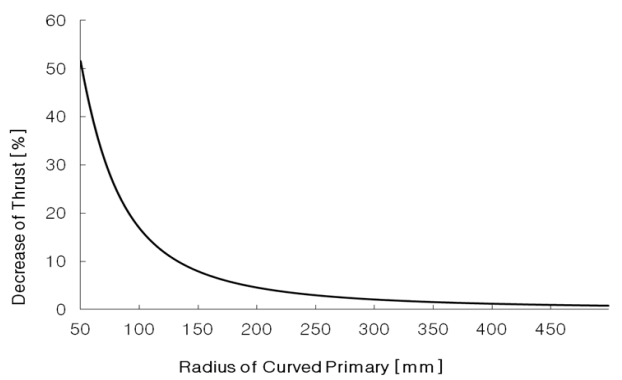

[Fig. 4] A decrease of thrust according to the radius of curve

To much decrease in the thrust at the curved part is not desirable and a big radius makes it difficult to install 
and assemble. So a suitable compromise was a number near $320[\mathrm{~mm}]$, number of poles was 16 , length of the armature was $510[\mathrm{~mm}]$. As a result considering the manufacturing error the radius of the curved part was readjusted to $326[\mathrm{~mm}]$. The rest of the parameter was determined like the plan sequence of the straight part. Also the movement field is a four pole and the armature is a 15 16 pole leaving the rest of the poles to make some leakage inductance resulting a voltage drop.

\section{LSM Implementation}

\subsection{Manufacturing the armature}

In producing the straight part of the armature was made by following the rules of making a general motor. However when connecting after stacking, the back of the armature core was bolted with rolled steel materials to make it more rigid. Because the core of the straight part was a lamination layer it was made by simply using a molding press. However the curved part core's inside and outside circumference was different in order to make 120 sheets of metal pins milling finishing was used.

A curved shaped angle bracket, which fastens and supports both cores on the outer side, was placed. The cores were pilled in a $90^{\circ}$ arc shaped form and were fixed to the top of the dividing head of the machine, and they were cut and manufactured based on the division of the rotating angle. Because 120 pieces of thin tin sheet plate are stacked together and cut out, the cores on the outer space of both sides can be damaged easily; therefore, for the safety issues, they must be welded together before the manufacturing process.

Fig. 5 demonstrates the measurement of the teeth of the comb and division angle of the core from the curved sections. The teeth of the comb was divided based on the cross section of the 'A', and the pitch of the teeth of the comb was set out to be the division angle, which is $1^{\circ} 46^{\prime}$, so that is can be equally divided in every $90^{\circ}$. The teeth of a comb has a thickness of $5.50[\mathrm{~mm}]$, and the comb structure split was designed so that the external diameter of the slot is $5.44[\mathrm{~mm}]$, while the internal diameter of the slot is $3.59[\mathrm{~mm}]$. However, it was difficult to divide the angles in a detailed manner with the end mill of the milling. By reducing the processing time, 1stroke slot was manufactured in the direction of the central axis of its circumference. As for the final product, the thickness of the external diameter of the comb structure is $5.50[\mathrm{~mm}]$, internal diameter of the comb structure is $3.65[\mathrm{~mm}]$; the depth of the comb structure split is $35.5[\mathrm{~mm}]$.

The fig. 6 represents the armature of the LSM produced.

' $\mathrm{X}$

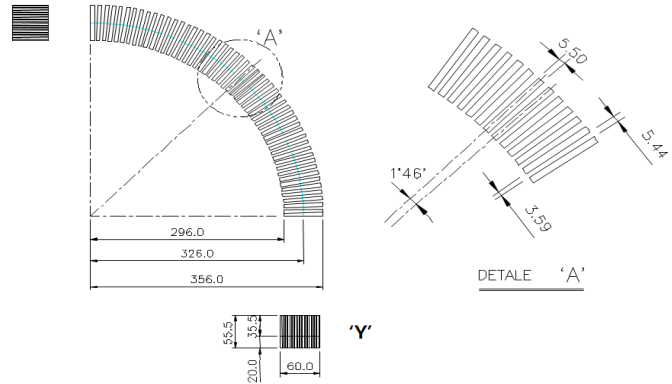

[Fig. 5] The measurement of the teeth of the comb and division angle of the core

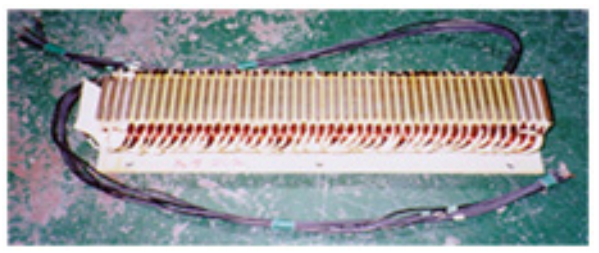

(a) straight part of armature

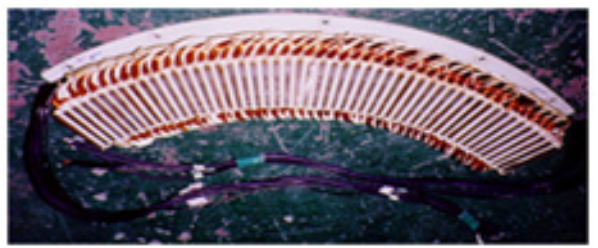

(b) curved part of armature

[Fig. 6] The armature of the LSM produced.

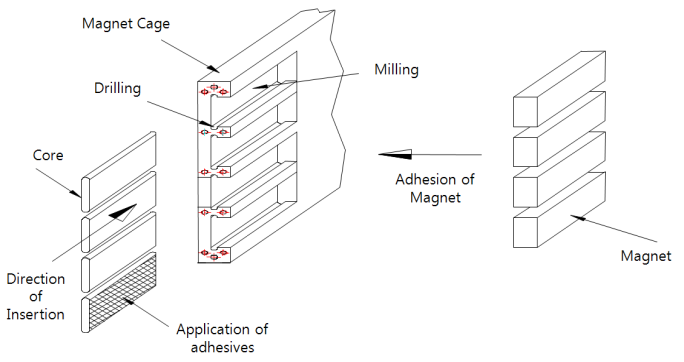

[Fig. 7] the manufacturing process of the mover 


\subsection{Producing of the movement field}

Fig. 7 shows the manufacturing process of the mover, which is the permanent magnet cage, and assembly drawing. Aluminum, a nonmagnetic material, was used for the permanent magnet cage.

Metal-to-metal adhesive was applied on the surface of the metal pin, and permanent magnets were pressed together and attached on top of it before inserting the permanent magnets into the cage. Fig. 8 displays the measurement of the mover that can be manufactured and actually be used. As for the permanent magnets, 16 of them were attached on both sides.

Based on the criteria stated above, fig. 9 represents the cross-sectional diagram of the bi-directional linear motor system. In this picture, the air-gap between the primary motor and the secondary permanent magnets was set to be $3[\mathrm{~mm}]$, and the guide rail was installed to maintain the air-gap.

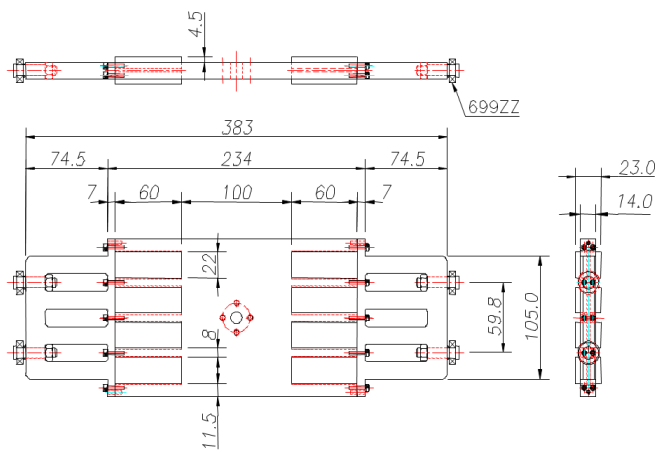

[Fig. 8] the measurement of the mover

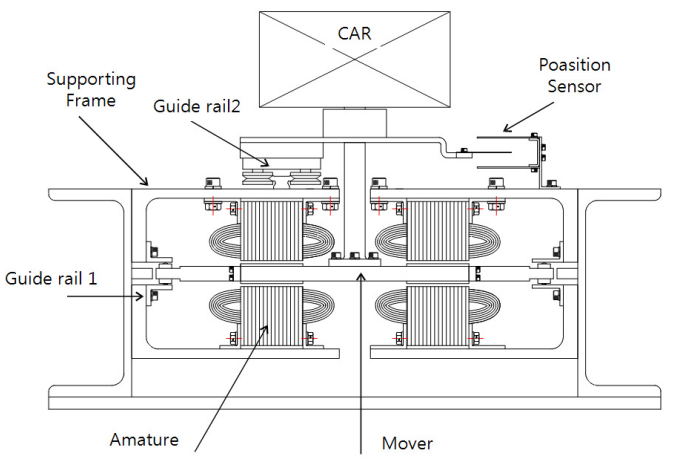

[Fig. 9] the cross-sectional diagram of the bi-directional linear motor system

\section{Characteristics Testing of LSM and Analysis Comparing}

In order to verify the design value, a value that was produced to test the basic characteristics of LSM, and the experimental value, a test device for the lock test was installed because it is hard to measure the thrust during any movement, which is shown in fig. 10. A load cell was used to measure the thrust, and finite element analysis was performed for characteristics analysis of LSM. Fig. 11 demonstrates the models of finite element analysis of LSM.

First of all, the thrust was measured based on the different phase angles on current 4[A], and Fig. 12 demonstrates the result of comparing the values of finite element analysis. Considering the error of the test apparatus and the measurement error, the values in the figure match accordingly despite the small differences in the thrust.

Secondly, by setting the maximum power angle gained from fig. 12 as a constant value, the fig. 13 shows the result and its comparison of the thrust on each different current. Likewise, the patterns correspond with one another despite the thrust difference.

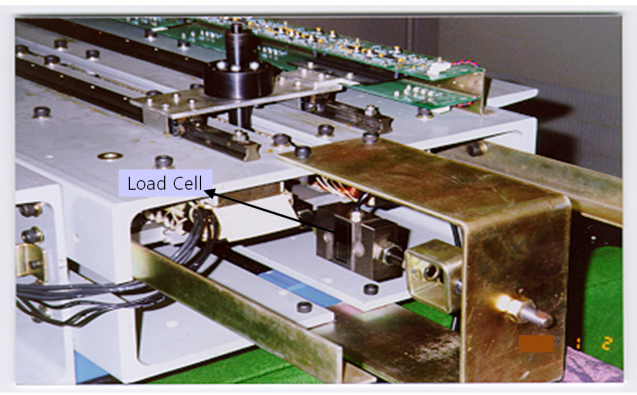

[Fig. 10] Thrust test device Figure

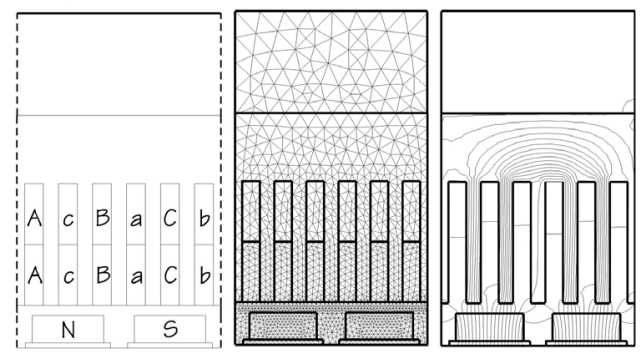

[Fig. 11] FEM Analysis model of LSM 


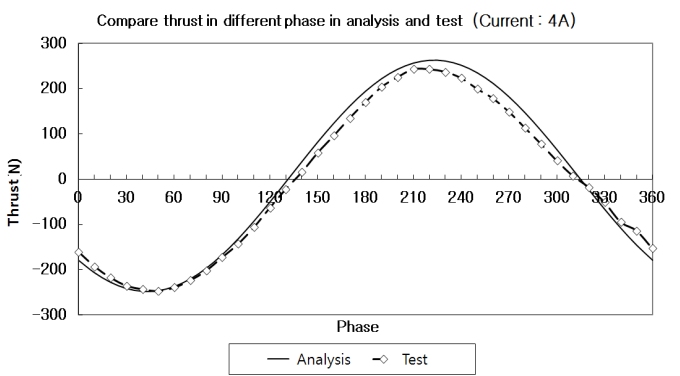

[Fig. 12] Compare thrust in different phase in analysis and test

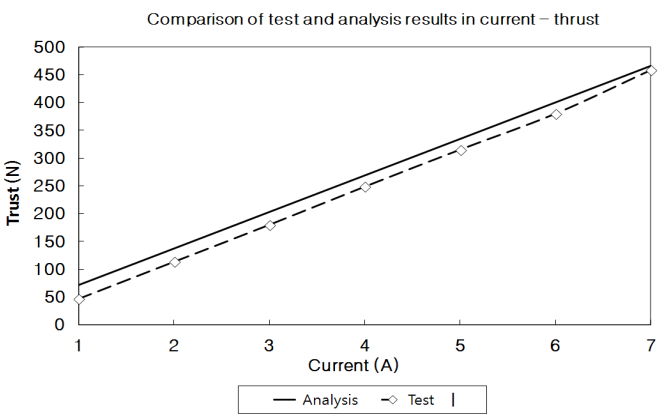

[Fig. 13] Comparison of test and analysis results in current vs thrust

\section{Driving test of pilot system}

\subsection{Speed Control Test}

In this study, proto type small ropeless elevator system's drive, we need velocity, position, and magnetic pole detecting sensor. It cannot be applied the primary rotational position sensor. So new linear encoder was designed and applied in this system. The design and manufacture of sensor were stated in detail in [9]. In this system, two inverters are connected to the primary LSM, and only the primary sections where the mover stands is driven. On the inverter sections, the current is controlled, and one main controller will perform the speed calculation and control speed.

In this paper, the small version of the ropeless elevator system for the purpose of verification test. First tested the performance of the speed control on the horizontal section. Fig. 14 shows the test waveform of the speed control based on the observer. Based on the test results, the speed controller based on the observer was used because it did not have the overshoot than the PI speed controller, and it took less time to reach the normal state. the detailed speed control results were reported previously in [9].

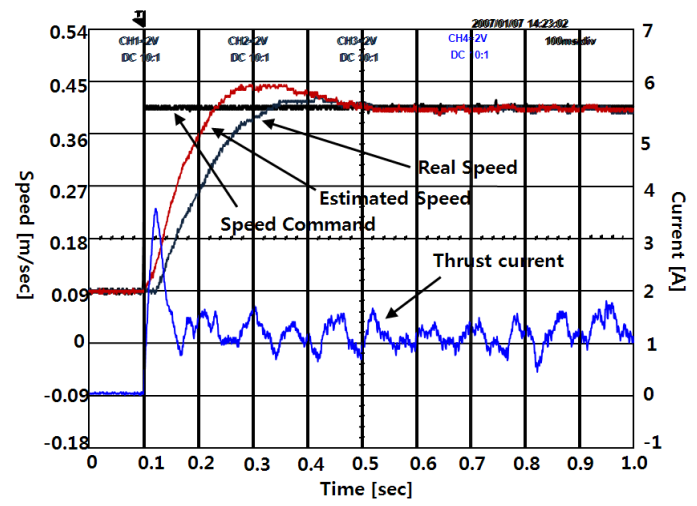

[Fig. 14] Speed and current waveform with disturbance observer according to step speed input

\subsection{Structure of the System \& Drive Test}

An overall control structure of the ropeless elevator pilot system is shown in fig. 15, and a connection diagram of the primary LSM system is presented in fig. 16. As shown in fig. 16, a primary LSM consists six straight sections and four curved sections, which sum up to ten parts. Since the system needs to be performed by two inverters, the relevant inverter was divided up into segments so that the cage with mounted permanent magnets, the section where the mover is, can receive power. A position sensor, which can detect the starting point and end point of each motor, was installed so that the signal divided up into segments occurs at the drive controller section of the main controller.

From each straight section, the linear encoder has an A and a B pulse sensor which identifies the velocity of $U$, $\mathrm{V}$, and $\mathrm{W}$ phases that can detect the simulating location of the mover; two position sensors are set up in all-in-one form inside the PCB for the motors that are placed into segments. Also, the length of one section is $480[\mathrm{~mm}]$, and the PCB size of the encoder was designed to be similar to a section of the linear motor for encoder mounting, in which it came out to be $470[\mathrm{~mm}]$. One PCB has a detection sensor in every $120 \mathrm{~mm}$, which is the length of the mover, so that when the mover moves nonstop, each signal can output continuously as well. 
In the main controller, the speed and position are calculated from the encoder, and a proper speed control is performed, inputting the command value of the current, the output, to the inverter. As for the current controller, two inverters are divided up into segments on the relevant primary, supplying the electric power.

Fig. 17 presents an assembly drawing of the entire pilot system of the ropeless elevator. The design model was mapped out so that secondary mover can run smoothly through a vertical, horizontal, and curved path inside a vertical building. The cage of the secondary mover is guided by the guide rail, and it was devised in a simplified testing environment within the weight limits. The guide rail was made by bending the $3.2[\mathrm{~mm}]$ thick flat iron board in " $\neg$ " shaped form so that it can be installed at the stator, also putting ball-and-roller bearing on one side of the board. The ball-and-roller bearing maintains the airgap by rolling on the rear surface of the guide rail. A caterpillar drive was used, and a curved track was installed in a $90^{\circ}$ fan-shaped form between the horizontal and vertical path so that it can run continuously.

Fig. 18 demonstrates the speed waveform of the drive in the ropeless elevator pilot system. Fig. 18 (a) shows a waveform of the drive when it starts from section IV and stops at section IX. When the mover is overlapped with section $\mathrm{V}$ as it accelerates, power is applied and is driven with section $\mathrm{V}$; section IV is cut off when it passes section IV, allowing section $\mathrm{V}$ to be driven independently. When it overlaps with section VI, which is a horizontal path, section VI is driven together with switching drive. The drive sequence, current, and speed waveform are shown in fig. 18. There is not much need for the thrust current in section VI; however, during section VII, VIII, and IX, in which the horizontal and curved sections descend, secondary thrust that opposes the gravitational force is created, controlling the speed.

Fig. 18 (b) shows a waveform of the drive when it starts from section IX and stops at section I. During section IX, which is a descending horizontal path, the system is driven by the secondary thrust, and the current is decreased during the curved section $\mathrm{X}$; the elevator is driven with a small amount of current in section $I$.

Although fig. 18 demonstrates successful speed and speed control from the current waveform, the irregular ripples are overall huge, showing how serious the fluctuation of the thrust current is on the segments of the system.

Because the system was not made accurately, the friction between the rails and air-gap fluctuation might have been severe enough to cause a large and irregular disturbance. Also, the huge ripple might have occurred due to the low speed resolution of the linear sensor.

Therefore for the commercialization of the ropeless elevator, a development on a contactless suspension, such as air suspension, is needed to gain low disturbance, as well as an improved research on current, speed controller, and a controller divided up into segments.

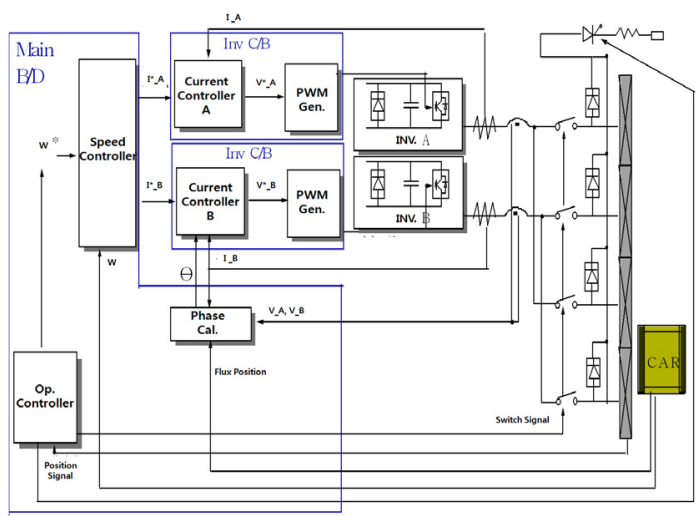

[Fig. 15] System configuration

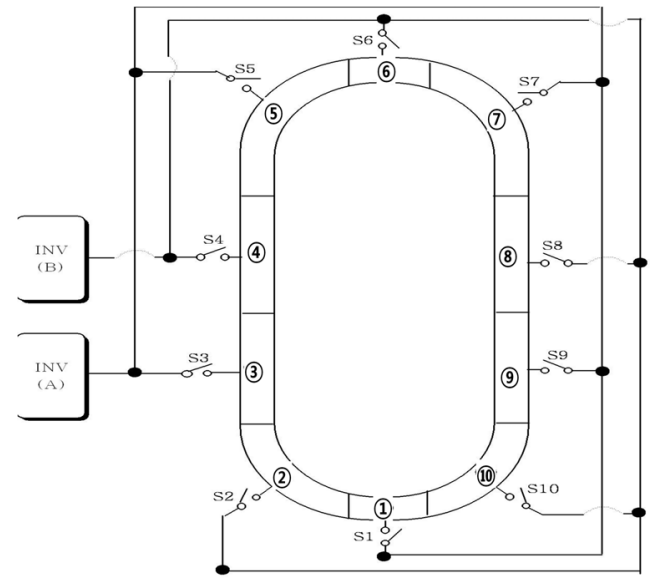

[Fig. 16] Switching system of stator 

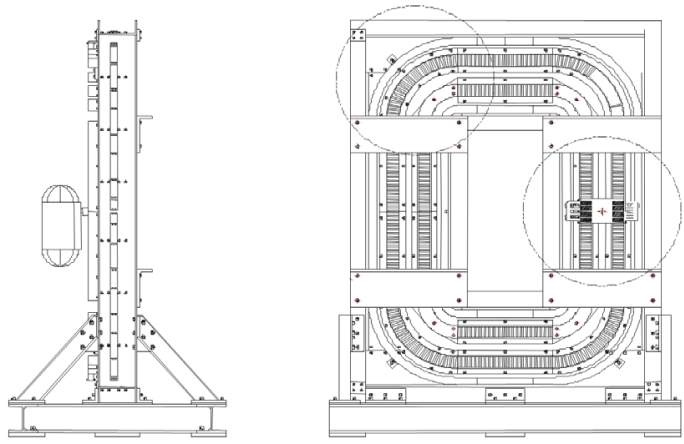

[Fig. 17] Assembly diagram of the pilot system

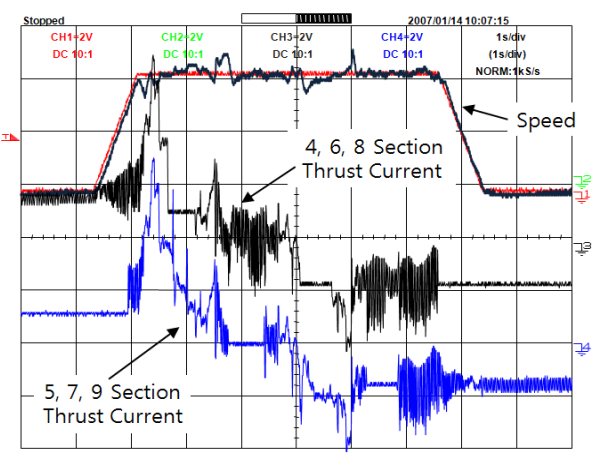

(a) section 4 to section 9

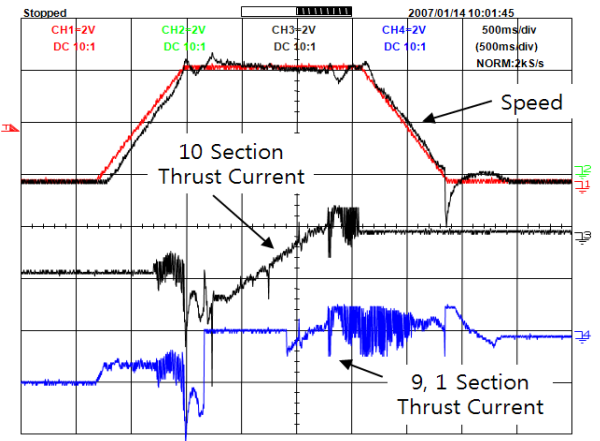

(b) section 9 to section 1

[Fig. 18] Driving test

\section{Conclusion}

This paper not only investigates the commercialization of the ropeless elevators, but also builds a foundation and suggests the necessary technology required for developing the ropeless elevator system by implementing prototype in a small scale. The paper also explores possible challenges that may occur during the development process of the ropeless elevator and provide ways to improve as well. For this research, a linear drive motor for the ropeless elevator was designed and produced, and especially curved linear motor, which is not widely studied, became the primary focus. A cross connection system was used for the operational control, and a disturbance observer and linear speed sensor for the flawless speed control.

There are, however, a number of problems that need to be solved for the purpose of the commercialization. The first one is the speed control problem caused by the low resolution of the linear speed sensor, in which a development on improved velocity sensor is very much desired for the higher resolution and commercialization. A second problem stems from a disturbance observer. Despite the effectiveness of the disturbance observer, the speed controller should be enhanced in order to suppress thrust ripple and vibration for a smoother ride. A third problem is the severe rail friction that can negatively affect the speed control and safety. Therefore, designing and developing a detailed structure with contactless suspension that can minimize the friction disturbance are needed. Although the last problem is not considered in this paper, rheostatic braking technique and various safety devices should be developed to prevent free fall of the elevator. Also, there should be a structural redesign to minimize the power consumption and improve the efficiency of the overall system through the reduction in loss and application of regenerative energy, and a research on having multiple cages in single shaft is needed for the future.

The ropeless elevator is not ready to operate in the field but complement and enhance technology development are made, it is possible to utilize for horizontal and vertical carrier systems within the buildings, such as the hospitals.

\section{References}

[1] T.Ishii, "Elevator for Skyscrapers", IEEE Spectr., vol 31, no 9, pp. 42-46, Sep. 1994.

DOI: http://dx.doi.org/10.1109/6.309960

[2] Paul Ueunten, "Propulsion and Guidance Simulation of a High-Temperature Superconducting Bulk Ropeless Linear Elevator", IEEE transactions on magnetics v.40 
no. 2 pt. 2 , pp.615 - 618,2004

DOI: http://dx.doi.org/10.1109/TMAG.2004.824573

[3] Yoshida K. ; Zhang X, "Propulsion and guidance control in ropeless linear elevator with pitching motion", Electrical Machines and Systems, 2005. ICEMS 2005. Proceedings of the Eighth International Conference on 2005 v.3, pp.1887 - 1892,2005

DOI: http://dx.doi.org/10.1109/ICEMS.2005.202890

[4] Schmulling, B, Effing, O, Hameyer, K, "state control of an electromagnetic guiding system for ropeless elevators", 2007 European Conference on Power Electronics and Applications, pp 1-10, Sept. 2007. DOI: http://dx.doi.org/10.1109/EPE.2007.4417287

[5] Sakamoto, T, Noma, Y, "Guidelines for VSS Controller Design of LSM-driven Ropeless Elevator", IEEE International Symposium on Industrial Electronics, Seoul, Korea July 5-8, pp. 1564 - 1568, 2009

DOI: http://dx.doi.org/10.1109/ISIE.2009.5215938

[6] Kang Do-Hyun, Ahn Jong-Bo, Kim Ji-Won, "Design of PM Excited Transverse Flux Linear Motor of Inner Mover Type", KIEE international trans. on electrical machinery and energy conversion systems v.5B no.2, pp.137 - 141, 2005

[7] H-Sun Lim, Krishnan R, "Ropeless Elevator With Linear Switched Reluctance Motor Drive Actuation Systems", IEEE transactions on industrial electronics, v.54 no.4, pp. 2209 - 2218, 2007

DOI: http://dx.doi.org/10.1109/TIE.2007.899875

[8] Sang-gun Lee, Koon-Seok Chung, Yu-Wu Zhu, Do-Sun Kim, Yun-Hyun Cho, "Detent Force Minimization of Permanent Magnet Linear Synchronous Motor for Ropeless Elevator System Using Response Surface Method", Proceeding of the 40th the KIEE Summer conference 2009, July14-17, pp.812-813, 2009

[9] Youn-Hyun Kim, “ Study of Drive Control System for Ropeless Elevator", Journal of the Korea AcademiaIndustrial cooperation Sciety, vol. 13, No. 8, pp.36343641,2012

DOI: http://dx.doi.org/10.5762/KAIS.2012.13.8.3634

\section{Youn-Hyun Kim}

[Regular member]

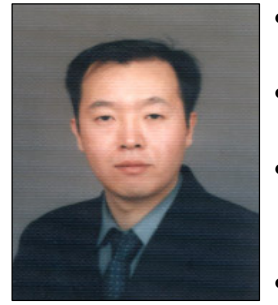

- Feb. 1989 : Hanyang Univ., Dept. of Electrical Eng., MS

- Feb. 2002 : Hanyang Univ., Dept. of Electrical Eng., $\mathrm{PhD}$

- Jan. $1989 \sim$ Aug. 1999 : LG Industrial System Co., Ltd., Senior Research Engineer

- Mar. $2003 \sim$ current : Hanbat Univ., Dept. of Electrical Eng., Professor

$<$ Research Interests $>$

Motor Design \& Drives

\section{Sol KIM}

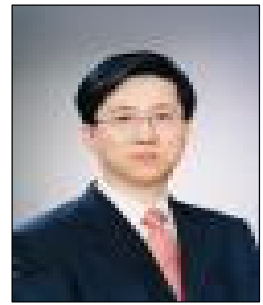

$<$ Research Interests $>$ Motor Design \& Drives
- Feb. 1999 : Hanyang Univ., Dept. of Electrical Eng., MS

- Feb. 2004 : Hanyang Univ., Dept. of Electrical Eng., PhD

- Sep. $2005 \sim$ current : Yuhan Univ., Dept. of Electrical Eng., Professor 